\title{
Article \\ Occlusal Splint Therapy Followed by Orthodontic Molar Intrusion as an Effective Treatment Method to Treat Patients with Temporomandibular Disorder: A Retrospective Study
}

\author{
Bálint Nemes ${ }^{1}$, Dorottya Frank ${ }^{2, *}$, Andreu Puigdollers ${ }^{3}$ and Domingo Martín ${ }^{4}$ \\ 1 Department of Paediatric Dentistry and Orthodontics, Faculty of Dentistry, Semmelweis University, \\ 1085 Budapest, Hungary; nemesbalintdr@gmail.com \\ 2 Department of Dentistry, Oral and Maxillofacial Surgery, University of Pécs, 7622 Pécs, Hungary \\ 3 Department of Orthodontics and Dentofacial Orthopaedics, Faculty of Dentistry, \\ International University of Catalunya, 08017 Barcelona, Spain; apuigdollersp@gmail.com \\ 4 Private Practice Martin-Goenaga, 20005 San Sebastián, Spain; domingomartin@domingomartin.com \\ * Correspondence: frank.dorottya@pte.hu; Tel.: +36-72-535-920
}

check for

updates

Citation: Nemes, B.; Frank, D.; Puigdollers, A.; Martín, D. Occlusal Splint Therapy Followed by

Orthodontic Molar Intrusion as an Effective Treatment Method to Treat Patients with Temporomandibular Disorder: A Retrospective Study. Appl. Sci. 2021, 11, 7249. https:// doi.org/10.3390/app11167249

Academic Editor: Mitsuru Motoyoshi

Received: 30 June 2021

Accepted: 3 August 2021

Published: 6 August 2021

Publisher's Note: MDPI stays neutral with regard to jurisdictional claims in published maps and institutional affiliations.

Copyright: (c) 2021 by the authors. Licensee MDPI, Basel, Switzerland. This article is an open access article distributed under the terms and conditions of the Creative Commons Attribution (CC BY) license (https:// creativecommons.org/licenses/by/ $4.0 /)$.

\begin{abstract}
Our goal is to show that temporomandibular disorder (TMD) patients with orthopaedic instability can be effectively treated by the combination of occlusal splint therapy and molar intrusion. Diagnostic records of 18 patients reporting previous TMD and treated with splint therapy were evaluated. Postsplint anterior open bite was treated by skeletally anchored molar intrusion. Changes in overjet $(\mathrm{OJ})$, overbite $(\mathrm{OB})$ were measured on articulator mounted models: initially in maximal intercuspidation (MI), centric "de jour", postsplint centric relation (CR) and postintrusion CR. Changes in ANB (A point-Nasion-B point) angle, mandibular plane-palatal plane angle and facial axis angle were assessed on lateral cephalograms. Morphological changes of the condyle were detected on pre-and posttreatment CBCT images. When compared screening mountings to MI models, significant differences were found in OJ and OB. Following splint wear, there was a significant increase in lower facial height and significant decrease in facial axis angle, which in turn increased ANB angle. OB and OJ showed a significant change on the postsplint mountings when compared to MI. After intrusion, mandible exhibited counterclockwise rotation, which decreased lower facial height, increased $\mathrm{OB}$ and facial axis angle and decreased ANB and OJ. Posttreatment CBCTs confirmed improved condylar morphology.Occlusal splint therapy followed by orthodontic molar intrusion provides MI-CR harmony, therefore, it seems to be an effective method for treating TMD patients.
\end{abstract}

Keywords: molar intrusion; orthodontic treatment; temporomandibular disorder; occlusal splint; centric relation

\section{Introduction}

Orthodontic treatment of patients with temporomandibular disorder (TMD) due to orthopaedic instability has always been challenging. Many clinicians advocate that the ideal occlusion should be related to an ideal condyle-disk-fossa relationship, what they refer to as centric relation (CR) [1]. TMD patients often show shift between maximal intercuspidation (MI) and CR [1,2]. Moreover the degree of CR-MI discrepancy has been shown to strongly correlate with the severity of the symptoms and signs of temporomandibular disorder (TMD) and therefore, it was proposed to be a contributory factor to the development of TMD [3]. Dawson and Roth were the first to explain how CR-MI discrepancy may lead to the development of TMD [4-6]. They declared that if CR interference exist during jaw closure, the inferior lateral pterygoid muscle is non-physiologically contracted in order to achieve MI. The contraction of the muscle distracts the condyle out of $\mathrm{CR}$ position resulting in hyperactivation of the elevator muscles. Imbalance between the elevator and depressor 
muscles can lead to consequent masticatory muscle spasm and pain $[4,5]$. As stated by Okeson; positional stability of the joint is determined by the muscles that pull across the joint and prevent separation of the articular surfaces. The muscles' directional forces determine the optimum, orthopedically stable joint position [7]. The continuous existence of occlusal interferences can contribute to chronic muscle hyperactivity, articular disc derangement and disc displacement which causes temporomandibular joint (TMJ) clicking and further progression will result in intracapsular disorders [4-6]. Over the years, the most preferably and commonly used therapy for treating patients with TMD with orthopaedic instability has been the occlusal stabilization splint [8]. Due to its design, it can reposition the mandible to $\mathrm{CR}$ and switch off the neuromuscular adaptation to MI by relaxing the muscles and achieve orthopaedic stability. Therefore, in orthodontic patients reporting TMD due to orthopaedic instability these stabilization splints are recommended prior to orthodontic therapy. During the splint wear, condyle is passively seated in the fossa, resulting in altered dental occlusion; contact on the most posterior teeth and anterior open bite (AOB) will develop $[9,10]$. Before the era of temporary anchorage devices (TADs), possible therapeutic solutions for adult AOB patients were camouflage treatment by extruding the anterior teeth, extraction, surgical maxillary impaction [11] and intrusion of posterior teeth by either intermaxillary [12] or extraoral appliances [13]. Shellhart [14] was the first who used dental implants for intruding molars. In 1996, Melsen and Fiorelli [15] demonstrated that significant amount of true orthodontic molar intrusion can be achieved which can largely facilitate the prosthetic reconstruction of partially edentulous patients and in the absence of gingival inflammation, it can improve periodontal health as well [16-18]. Since then, many techniques have been introduced for skeletally anchored posterior teeth intrusion [19-25]. Although, in many of these articles, intrusion mechanics, force magnitudes and treatment details are precisely described, not too much attention has been paid towards the real condyle position so far. Besides, far less is mentioned about the shape and position of the condyle seen in $3 \mathrm{D}$ as in CBCT images. In turn, treatment started from and ended in CR-where the condyle is centered in the fossa and the disc position is correct-with orthopaedic stability, can be one of the assurances for long-term occlusal stability and temporomandibular joint (TMJ) health. Accordingly, not considering CR in these patients may query even the real start-, and endpoint of the treatment and the stability as well. Therefore, the aim of the present study is to present the results of a series of 18 consecutive cases with orthopaedic instability treated with occlusal splint therapy followed by skeletally anchored molar intrusion, and studied by pre and posttreatment articulator mounting, lateral cephs and CBCT.

\section{Materials and Methods}

\subsection{Subjects}

In our study, pre-and posttreatment diagnostic records of 47 orthodontic patients with TMD (18 men, 29 women, mean age: 35.3 years) treated at a private praxis between 20082018 were evaluated. Table 1 summerizes the age and gender distribution of the subjects.

All of the patients were diagnosed with orthopaedic instability and had complaint of muscle pain (masseter, temporal, medial pterygoid and/or suboccipital), 31 subjects had reversible disc dislocation (13 unilateral, 18 bilateral) and 16 patients had disc displacement without reduction and therefore, were treated with full-coverage hard acrylic occlusal splints. After achieving an orthopaedic stability and the elimination of TMD, postsplint AOB was treated by non-surgical orthodontic approach. From the original 47 patients, only 18 patients ( 2 men, 16 women; mean age 28.7 years) were included in the study. 29 were excluded due to missing diagnostic records, no use of skeletal anchors, lack of proper compliance in full-time splint wear and because of moving to another location. Molars were intruded by buccal zygomatic miniplates with combination of either palatal miniscrews or transpalatal bars. In two cases where dental implants were present, these implants were used to facilitate intrusion (Figure 1a-f). 
Table 1. Age and gender distribution of the subjects.

\begin{tabular}{ccc}
\hline & & Gender \\
& Men & Women \\
\hline Number of subjects & 18 & 29 \\
\hline Mean age (years) & 35.42 & 35.27 \\
\hline Age range (years) & & \\
\hline $10-20$ & 0 & 2 \\
\hline $21-30$ & 8 & 8 \\
\hline $31-40$ & 6 & 3 \\
\hline $41-50$ & 2 & 3 \\
\hline $51-60$ & 0 & 1 \\
\hline $61-70$ & 2 & \\
\hline
\end{tabular}
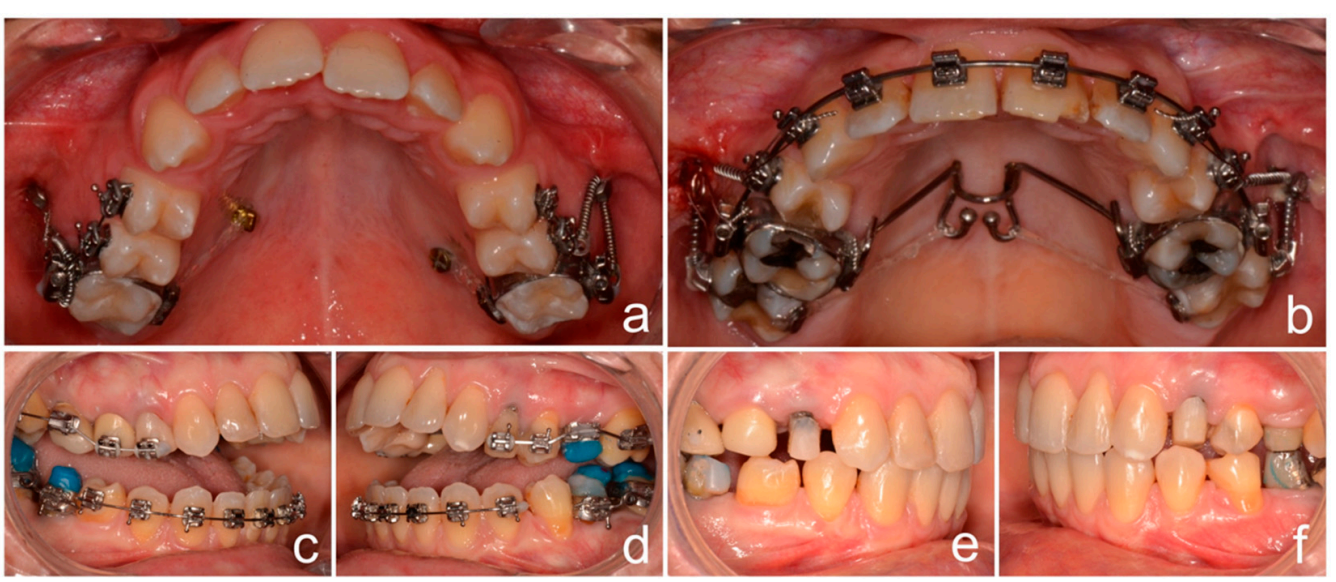

Figure 1. Skeletally anchored molar intrusion. Buccal miniplates combined palatal miniscrews (a) or with transpalatal bar (b) or bilateral molar dental implants $(\mathbf{c}-\mathbf{f})$ were used for orthodontic molar intrusion following occlusal splint therapy.

Occlusal bite blocks were used to enhance intrusion and maintain CR position. Average intrusion was $1.95 \pm 0.58 \mathrm{~mm}$ and following intrusion the maxillary molars were ligature tied to the TADs. The average treatment time was $22 \pm 2.5$ months. The study was conducted in accordance with the Declaration of Helsinki Ethical Principles and Good Clinical Practices and was approved by the Clinical Research Ethics Committee of the University Hospital Sta.Universitario $\mathrm{M}^{\mathrm{a}}$ del Rosel, Areas II and VIII of Health of the Murcian Health Service (El ID: EO 19/52. Intrusion molar ortodoncia).

\subsection{Model Analysis}

Panadent articulators (IML GmbH, Germany) were used for all mounting processes. Overjet $(\mathrm{OJ})$ and overbite $(\mathrm{OB})$ were evaluated on the pre-and posttreatment articulator mounted models in four positions by using a Pittsburg digital caliper (Harbor Freight Tools, Calabasas, CA, USA):

$\mathrm{T} 0^{\mathrm{MI}}$. Initially in $\mathrm{MI}$ and $\mathrm{T} 0^{\mathrm{CR}}$. in centric "de jour"

T1. In CR after 3-12 months of full-time splint wear with a stable joint position

T2. In CR after molar intrusion

Changes in $\mathrm{OJ}$ and $\mathrm{OB}$ were then calculated between the mounted positions $\left(\mathrm{T} 0^{\mathrm{MI}} \mathrm{vs}\right.$. $\mathrm{T}^{\mathrm{CR}}, \mathrm{T} 0^{\mathrm{MI}}$ vs. $\mathrm{T} 1, \mathrm{~T} 1 \mathrm{vs}$. T2). The criteria of stable CR position were the followings: No signs and symptoms of TMD (muscle tenderness, pain, clicking, locked joint), no change regarding the contact points on the splint for at least 3 appointments (12 weeks) and easy manipulation of the mandible by the clinician. 


\subsection{Centric Relation Registrations}

All CR registrations were performed with dual wax bite method. The registrations were taken with hard wax (Almore, Beaverton, OR, USA) in two sections; anterior and posterior. The anterior section consisted of a 4-layer softened wax and included both upper and lower anteriors (canine to canine). First, patients were instructed to close gently on the arc of mandibular closure without protrusion, until approximately $2 \mathrm{~mm}$ of space remained between posterior-most teeth. In order to remove the wax without distorsion, patients were instructed to hold this position until wax was cooled and hardened. Following, a posterior 2-layer-thick softened wax was inserted together with the previously obtained hard anterior wax and then mandible was slightly guided into CR. At the end, subjects were instructed to close firmly and hold until the posterior section cooled and hardened as well.

\subsection{Cepahlometric Measurements}

Initial presplint (T0), postsplint (T1) and final posttreatment (T2) lateral cephalograms of the subjects were evaluated. T0 cephs were taken in MI position. For T1 cephs, wax bites were prepared (Beauty Pink Wax X, Miltex, York, PA, USA) based on the stable $\mathrm{CR}$ position achieved via splint wear. Wax bites were constructed in the CR mounted articulator with first contact on the most posterior teeth. Postintrusion T2 cephs were captured in MI position which was equivalent (MI-CR discrepancy less than $0.5 \mathrm{~mm}$ ) with CR as checked on the mounted casts. As described in Table 2, ANB angle, vertical jaw relationship (Mandibular plane-Palatal plane angle) and Facial axis angle by Ricketts were evaluated on the lateral cephalograms.

Table 2. Definitions of cephalometric measurements used in this study.

\begin{tabular}{cc}
\hline Measurement & Definition \\
\hline ANB angle & A point-Nasion-B point angle \\
\hline Palatal plane-Mandibular plane angle & $\begin{array}{c}\text { Angle between Posterior nasal spine-Anterior nasal } \\
\text { spine and Gonion-Menton }\end{array}$ \\
\hline Facial Axis angle by Ricketts & $\begin{array}{c}\text { Angle between Nasion-Basion and the facial axis } \\
\text { (Pterygomaxillare-Gnathion) }\end{array}$ \\
\hline
\end{tabular}

All tracings and superimpositions were performed digitally. Lateral cephs were superimposed by using cranial base and skull contours. Landmarks necessary for above mentioned measurements were marked and differences between $\mathrm{T} 0 \mathrm{vs}$. $\mathrm{T} 1$ and $\mathrm{T} 1 \mathrm{vs}$. T2 were evaluated.

\subsection{Condylar Morphological Evaluation Using Bilateral CBCT Scans of TMJ}

Pre-and posttreatment bilateral CBCT (NewTom, Verona, Italy) images of the TMJ were used to assess condylar position, detect any existing signs of internal derangement and monitor condylar morphological changes following the orthodontic treatment. Exposure parameters were identical for all subjects. CBCT data of all patients were evaluated in sagittal and coronal sections by two examiners blinded for the clinical diagnosis (neither knowing if the CBCTs were taken pre-or posttreatment). In case of disagreement a third examiner was asked in order to reach a final agreement. The most frequent osseous changes were examined in the CBCT images of the right and left TMJ areas according to criteria used in previous studies at $[26,27]$ :

1. Flattening of the articular surface- loss of an even convexity of the joint (Figure 2a-d)

2. Surface erosion (decreased density of the cortical and adjacent bone) and/or condylar surface irregularity (loss of continuity of condylar cortex) (Figure 2b)

3. Absence of condylar anterosuperior position and/or apparent irregular TMJ joint space (Figure 2c) 
4. Sclerosis (increased density of cortical bone extending into the bone marrow) (Figure 2d)



Figure 2. Representative CBCT images of the most frequent osseous changes of TMJ; flattening (a), surface erosion associated with surface irregularity (b), irregular TMJ joint space (c), sclerosis (d).

\subsection{Statistical Analysis}

All statistical analyses were performed using R Core Team (2018), R: A Language and Environment for Statistical Computing statistical software. Tracings of all lateral cephalograms were done by one examiner. To measure intraexaminer reliability, repeated tracings of all cephalograms and model measurements were done after 2 weeks. To determine the repeatability of measurements, mixed-effects model was used. In every examined variable, repetition had no significant effects on measure outcomes, supporting good intraexaminer reliability. To evaluate changes in OJ, OB and cephalometric parameters during the treatment multiple comparison correction was performed by repeated measures ANOVA followed by Turkey post hoc test. In order to verify differences in frequencies of pre-and posttreatment joint derangements McNemar's chi-square test was used with continuity correlation. Namely after the blinded examination, the pre- and posttreatment samples were re-paired again and as far as, there were no retrogression among the subjects, only those samples were included in the statistical analysis were pretreatment symptoms were detected. Statistically significant differences between groups were defined at $p$ values $<0.05$.

\section{Results}

Table 3 represents the means, the lower (CI.l) and upper (CI.u) limits of $95 \%$ confidence interval of the changes between $\mathrm{T} 0^{\mathrm{MI}}$ vs. $\mathrm{T} 0^{\mathrm{CR}}, \mathrm{T} 0^{\mathrm{MI}}$ vs. $\mathrm{T} 1$ and $\mathrm{T} 1 \mathrm{vs}$. $\mathrm{T} 2$ mountings for $\mathrm{OJ}$ and $\mathrm{OB}$ and Table 4 changes between $\mathrm{T} 0$ vs. $\mathrm{T} 1$ and $\mathrm{T} 1 \mathrm{vs.}$. 22 lateral cephs for the selected cephalometric variables, respectively. 
Table 3. Changes in $\mathrm{OJ}$ and $\mathrm{OB}\left({ }^{*} p<0.05\right)$.

\begin{tabular}{cccccc}
\hline & & Mean & CI.1 & CI.u & $p$ Value \\
\hline \multirow{3}{*}{ OB } & $\mathrm{T}^{\mathrm{MI}}$ vs. T0 & -1.3333 & -2.2082 & -0.4585 & $0.0005^{*}$ \\
\cline { 2 - 6 } & $\mathrm{T}^{\mathrm{MI}}$ vs. T1 & -3.1389 & -4.0137 & -2.2641 & $0.0000^{*}$ \\
\cline { 2 - 6 } & $\mathrm{T} 1$ vs. T2 & 4.0278 & 3.1529 & 4.9026 & $0.0000^{*}$ \\
\hline \multirow{2}{*}{ OJ } & $\mathrm{T}^{\mathrm{MI}}$ vs. T0 & 1.2222 & 0.3367 & 2.1078 & $0.0022^{*}$ \\
\cline { 2 - 6 } & $\mathrm{T}^{\mathrm{MI}}$ vs. T1 & 2.5833 & 1.6978 & 3.4689 & $0.0000^{*}$ \\
\cline { 2 - 6 } & $\mathrm{T} 1$ vs. T2 & -2.0556 & -2.9411 & -1.1700 & $0.0000^{*}$ \\
\hline
\end{tabular}

Table 4. Changes in Mandibular plane-Palatal plane angle, Facial axis angle by Ricketts and ANB angle $(* p<0.05)$.

\begin{tabular}{cccccc}
\hline & & Mean & CI.1 & CI.u & $p$ Value \\
\hline \multirow{2}{*}{$\begin{array}{c}\text { Mandibular plane- } \\
\text { Palatal plane angle }\end{array}$} & T0 vs. T1 & 2.5778 & 1.776 & 3.3800 & $0.0000^{*}$ \\
\cline { 2 - 6 } Facial axis angle by Ricketts & T1 vs. T2 & -2.8333 & -3.635 & -2.0311 & $0.0000^{*}$ \\
\cline { 2 - 6 } & T0 vs. T1 & -1.6667 & -2.684 & -0.649 & $0.0004^{*}$ \\
\cline { 2 - 6 } & T1 vs. T2 & 2.3333 & 1.316 & 3.351 & $0.0000^{*}$ \\
\hline \multirow{2}{*}{ ANB angle } & T0 vs. T1 & 1.4722 & 0.8474 & 2.0971 & $0.0000^{*}$ \\
\cline { 2 - 6 } & T1 vs. T2 & -1.6667 & -2.2915 & -1.0418 & $0.0000^{*}$ \\
\hline
\end{tabular}

When compared screening mountings to models in $\mathrm{MI}\left(\mathrm{T} 0^{\mathrm{MI}}\right.$ vs. $\left.\mathrm{T} 0^{\mathrm{CR}}\right)$ significant differences were found in horizontal and vertical overlap of the incisors. OB decreased by $1.33 \pm 0.73 \mathrm{~mm}(p=0.0005)$ while OJ increased by $1.22 \pm 0.69 \mathrm{~mm}(p=0.0022)$.

Following full time acrylic splint wear (T0 vs. T1), there was a significant average increase $\left(2.58^{\circ} \pm 0.93^{\circ}\right)(p=0.0000)$ in lower facial height (palatal plane-mandibular plane angle) and a significant decrease in facial axis angle $\left(1.67^{\circ} \pm 1.54^{\circ}\right)(p=0.0004)$, which in turn had a sagittal effect as the ANB angle increased significantly by $1.47^{\circ} \pm 0.70^{\circ}$ $(p=0.0000)$. Consequently, both $\mathrm{OB}$ and $\mathrm{OJ}$ showed a significant change on postsplint mountings when compared to centric occluded models ( $\mathrm{T} 0^{\mathrm{MI}}$ vs. $\mathrm{T} 1$ ); $\mathrm{OB}$ had an average decrease of $3.14 \pm 1.65 \mathrm{~mm}(p=0.0000)$ and OJ an average increase of $2.58 \pm 1.51 \mathrm{~mm}$ $(p=0.0000)$.

In every examined variable, molar intrusion (T1 vs. T2) resulted in statistically significant changes as well. After intrusion of the molars, mandible exhibited counterclockwise rotation, which was confirmed by decreased lower facial height and increased $O B$ $(4.03 \pm 1.88 \mathrm{~mm}(p=0.0000))$, decreases in ANB and OJ. The palatal plane-mandibular plane angle decreased by $2.83^{\circ} \pm 1.78^{\circ}(p=0.0000)$, the ANB angle by $1.67^{\circ} \pm 1.12^{\circ}$ $(p=0.0000)$ and the OJ by $2.06 \pm 2.13 \mathrm{~mm}(p=0.0000)$. The mean change in facial axis angle was $+2.33^{\circ} \pm 2.08^{\circ}(p=0.0000)$.

Figure 3 a shows representative superimpositions of T0 vs. T1 and Figure $3 \mathrm{~b}$ superimpositions of T1 vs. T2 lateral cephalographs, respectively.

When comparing pre -and posttreatment CBCT images of TMJ, the frequency of derangement was found to be different on the left and right sides. Table 5 summarizes the pre-and posttreatment frequencies of TMJ alterations. On the right side, flattening before the treatment was seen in $61.11 \%$ and $72.22 \%$ on the left side, which showed a significant improvement to $27.78 \%$ on the right and $38.89 \%$ on the left side following intrusion (posttreatment). Assessment of the CBCT findings of surface erosion and irregular condylar surface showed $72.22 \%$ on the right and $55.56 \%$ on the left side which significantly decreased to $22.22 \%$ on both posttreatment sides. Irregular TMJ space and/or absence of anterosuperior position of the condyle was $66.67 \%$ on the right and $61.11 \%$ on the left side, which significantly improved, as only $16.67 \%$ of the patients showed still nonideal 
posttreatment condylar position. No pre-and posttreatment differences were found in sclerosis, as the frequency remained $22.22 \%$ of the right and $11.11 \%$ of the left TMJ.
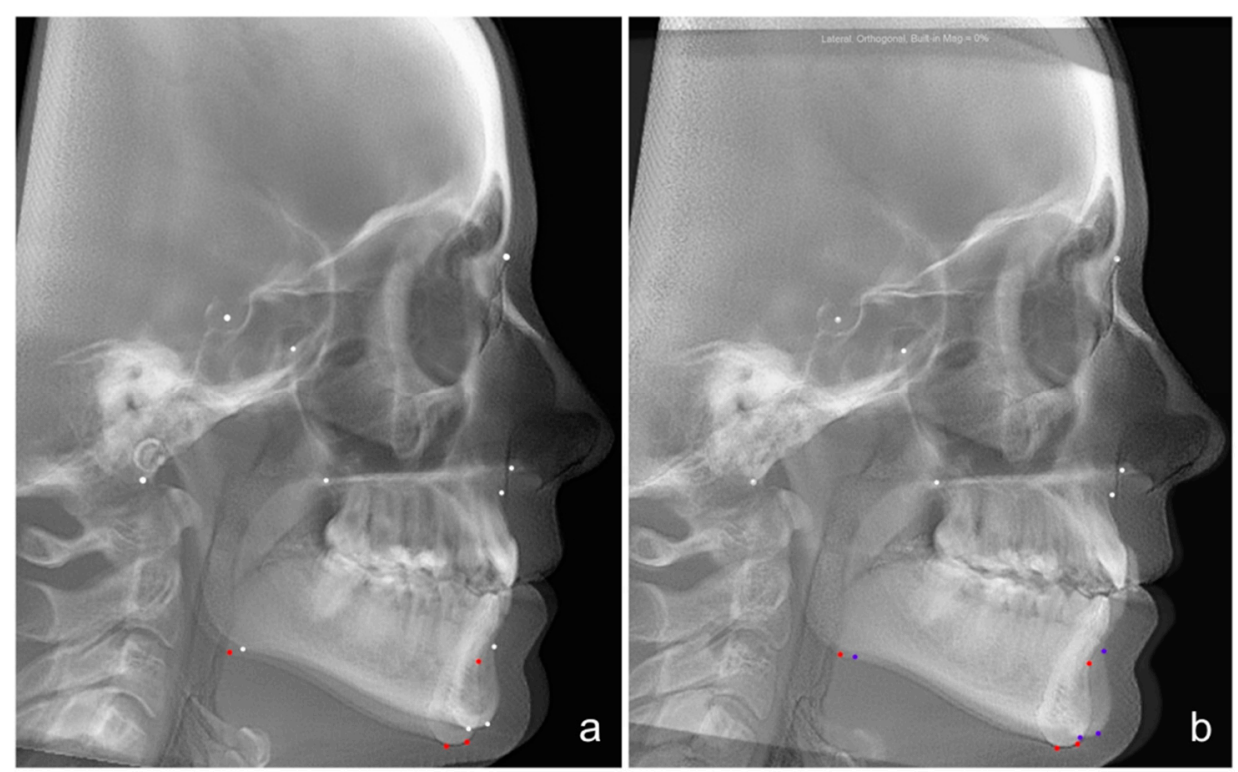

Figure 3. Representative superimpositions of presplint (T1) vs. postsplint (T2) (a) and postsplint (T2) vs. postintrusion (T3) (b) lateral cephalograms. Following splint wear (a), there was a significant increase in lower facial height and significant decrease in facial axis angle, which in turn increased ANB angle. After intrusion (b), mandible exhibited counterclockwise rotation, which was confirmed by decreased lower facial height, increased $\mathrm{OB}$ and facial axis angle and decreases in ANB.

Table 5. Frequency of osseous changes before and after therapy $(* p<0.05)$.

\begin{tabular}{|c|c|c|c|c|c|c|}
\hline Morphological Signs & $\begin{array}{c}\text { Pretreatment } \\
\text { Right }\end{array}$ & $\begin{array}{c}\text { Posttreatment } \\
\text { Right }\end{array}$ & $p$ Value & $\begin{array}{c}\text { Pretreatment } \\
\text { Left }\end{array}$ & $\begin{array}{c}\text { Posttreatment } \\
\text { Left }\end{array}$ & $p$ Value \\
\hline Flattening & $61.11 \%$ & $27.78 \%$ & $0.0412 *$ & $72.22 \%$ & $38.89 \%$ & 0.0412 * \\
\hline $\begin{array}{c}\text { Surface erosion, } \\
\text { surface irregularities }\end{array}$ & $72.22 \%$ & $22.22 \%$ & 0.0077 * & $55.56 \%$ & $22.22 \%$ & 0.0412 * \\
\hline Irregular TMJ space & $66.67 \%$ & $16.67 \%$ & 0.0077 * & $61.11 \%$ & $16.67 \%$ & 0.0133 * \\
\hline Sclerosis & $22.22 \%$ & $22.22 \%$ & 1 & $11.11 \%$ & $11.11 \%$ & 1 \\
\hline
\end{tabular}

\section{Discussion}

Treatment of orthodontic patients with TMD due to orthopaedic instability has always been challenging especially as one of the desired outcomes of the orthodontic therapy is the achievement of an orthopaedic stability with an ideal harmony between occlusal functions and TMJ [1]. Many case studies are available demonstrating TMD patients treated with stabilization splint and/or molar intrusion [5,22,23,28-30]. But, so far a series of larger number of TMD orthodontic subjects, treated by stabilization splint followed by molar intrusion, with the main focus on TMJ health and CR-MI harmony have not been examined so extensively and studies have not been published yet. The aim of our study was to investigate and demonstrate that TMD patients with an orthopaedic instability can be effectively treated by the occlusal splint therapy followed by skeletally anchored molar intrusion.

TMD is by far a complex disease and the nature of it is not completely understood [31,32]. Most common signs and symptoms are masticatory muscle pain, TMJ sounds, limited movements (jaw opening capacity and deviations in mandibular movements), which tend to fluctuate with temporary remissions [33,34]. It has been generally accepted that 
TMD has a multifactorial origin [28]. There is still a debate, whether occlusion plays a role in the etiology of TMD, nevertheless, completely rejecting the role of it may be inappropriate $[1,35]$. It has been reported that TMD is closely associated with some type of malocclusions, such as open bite, deep bite and posterior cross bite [29]. Disharmony between CR-MI has been suggested to be a causative factor as well $[2,5]$ and it has been showed that the degree of CR-MI discrepancy has a strong positive correlation with the severity of TMD signs and symptoms $[3,5]$ and by achieving harmony between CRMI during the orthodontic treatment decreases the risk of TMD. According to this, the mandible should seat ideally into MI during closure without condylar deflection from CR position caused by occlusal interferences $[4,36,37]$. Therefore, CR-MI harmony should be one of the major goals of the orthodontic treatment. In most of the published literature that have failed to prove an existing relationship between occlusion and TMD, several inadequacies are present; such as no instrumentation was used. Most of the studies used only questionnaires, clinical examinations and only dental cast [38,39]. In a review, McNamara, Seligman and Okeson have also found relative low association between TMD and occlusal factors, although in the studies they reviewed, the occlusions were evaluated only intraorally and by using chin-point evaluation [40]. No attempt has been made to examine the condylar position and the possible effect on the stability of the TMJ by means of articulator models or precise determination of condyle with 3D imaging. To assess both condylar and occlusal relationships, articulator mounted models are recommended [41-43]. In our study, all diagnostic cast were mounted into articulators at different stages of the treatment; initially in $\mathrm{MI}\left(\mathrm{T} 0^{\mathrm{MI}}\right)$, in centric "de jour" $\left(\mathrm{T} 0^{\mathrm{CR}}\right)$, after splint wear in $\mathrm{CR}(\mathrm{T} 1)$ and following molar intrusion in CR (T2), therefore we could monitor condyle position. We found significant CR-MI disharmony between the screening mountings and the initial records. The discrepancy was even more expressed when we compared the initial models with the postsplint ones, where following deprogramming the neuromuscular avoidance patterns were not present making the condylar seating accurate. These results are in agreement with He et al., who investigated the relationship between CR-MI discrepancy and TMD have found that CR-MI shift is strongly correlated with the signs and symptoms of TMD [3]. For TMD treatment, various methods have been used, including physio- and relaxation therapy, pharmacological interventions, arthroscopic surgery, behavioral and educational counseling and occlusal splints as well $[44,45]$. Pharmacologic therapies mainly aim to reduce pain and inflammation. There is growing interest for the use of polyphenols, however their beneficial effects on modulation of oxidative stress and inflammation remain highly limited due to their low bioavailability and bio-transformation [46]. A recent network meta-analysis of randomized controlled trials showed that hard stabilization splints in conjunction with counselling therapy can produce maximum benefit for TMD patients, furthermore, hard stabilization splint is far superior in patients with myogenous TMD [47]. Recently, randomized clinical trials have indicated that stabilization splints are superior to other treatments for TMD due to orthopaedic instability [34,44]. These splints are made of hard acrylic material, which can eliminate occlusal interferences, reduce abnormal muscle activity and therefore provide good neuromuscular balance. Splint therapy has been shown to be effective in changing the occlusal pattern of the teeth and improving the function of the masticatory system [35,45,48]. All patients included in the present study received full coverage acrylic splint therapy prior to the orthodontic treatment, in order to eliminate the signs and symptoms. Patients were instructed to full-time splint wear, as strong association between wearing time and effectiveness had been previously reported [47]. Following the splint wear altered occlusal relationship; AOB develops, which should be corrected. Molar intrusion is one of the most valid treatment approaches used for open bite corrections [49]. It has a similar effect to surgery in that sense that the upward molar repositioning autorotates the mandible in counter-clockwise direction (up- and forwards) and as an indirect consequence the incisor relationships will improve as well. Compared to orthognathic surgery application of TADs requires no compliance, has low risk and morbidity, is less expensive and invasive and more 
acceptable by patients. Several studies investigated the biological processes involved in molar intrusion [50,51]. In animal studies, alveolar bone and nasal/sinus floor remodeling without pulp vitality loss and clinically significant root resorption have been found to occur during and following molar intrusion [50,51]. Furthermore, micro-CT studies of human teeth has also confirmed that root resorption following molar intrusion is clinically insignificant [19]. Moreover, Akan et al. [23] demonstrated that molar intrusion has no negative effect on TMJ and masticatory system. According to these, in all subjects, TADs were used in order to correct $A O B$ developed after splint wear. In our study, after intruding molars, mandibular counterclockwise rotation occurred toward closing the bite, which in turn induced up-and forward displacement of the B point as well as reduction in the $\mathrm{ANB}$, mandibular plane angle and anterior facial height. The average mandibular rotation seen in our patients was $2.8^{\circ}$, which is similar to others [19,22-25]. Regarding the dental changes, following molar intrusion we found an average increase in $\mathrm{OB}$, which is similar change observed by others as well [22,52,53].

So far, numerous imagining techniques have been used to evaluate morphological changes of the TMJ. Panoramic radiographs have 2D limitations and low sensitivity due to structural distortion and superimposition of the zygomatic process [54]. For visualization of disc-condyle relationship Magnetic Resonance Imagining (MRI) technique has been used as the gold standard diagnostic method [55]. CT can be used to detect bony changes, however, besides its high diagnostic efficacy, СBCT has several advantages over it, such as; lower radiation dose, better accessibility, lower cost [56]. In this study we used CBCT to evaluate the pre-and posttreatment (following intrusion) condylar morphology. Among the 18 patients with orthopedic instability, flattening, surface erosion and surface irregularities were the most frequent pretreatment bony changes. This is in agreement with Shahidi et al., who found flattening in $73.3 \%$ of TMJ related symptomatic cases [27]. When comparing pretreatment and posttreatment joints, except the sclerosis, significant improvements were seen following treatment in the three examined variables on both sides; approximately $50 \%$ of the condylar surfaces regained their convexity, cortical bone continuity and condylar position improved by about $40 \%$. In previous study, flattening was found to show positive correlation with TMD [26]. Those studies, where no correlation has been found between TMD and morphological changes, the high prevalence of bony changes in asymptomatic patients was explained by the adaptive and compensatory potential of the TMJ [57]. Furthermore, a systematic review pointed out a potential sample selection bias among the papers comparing morphological changes between TMD and non-TMD patients; namely, in most studies patients included in those studies were referred to TMD and facial pain services, meaning that only asymptomatic and not the healthy control group could have been assured [58]. In summary, our results highlighted that occlusal splint therapy followed by orthodontic molar intrusion has a positive impact on bony changes of the TMJ.

\section{Conclusions}

The results of this study showed that occlusal splint therapy followed by skeletally anchored molar intrusion is an effective treatment method for patients with TMD as it provides CR-MI harmony, therefore orthopaedic stability and favourable bony changes of the TMJ.

Author Contributions: B.N. contributed to data collection, performed all the measurements, statistical analysis and was involved in manuscript drafting. D.F. contributed to planning the study design was involved in data analysis and interpretation and was the major contributor to writing the manuscript. A.P. was involved in data analysis and manuscript writing. D.M. was the supervisor of the overall project, critically revised the final version of the manuscript and has the overall responsibility. All authors have read and agreed to the published version of the manuscript.

Funding: This research received no external funding. 
Institutional Review Board Statement: The study was approved by the Clinical Research Ethics Committee of the University Hospital Sta.Universitario $\mathrm{M}^{\mathrm{a}}$ del Rosel, Areas II and VIII of Health of the Murcian Health Service (El ID: EO 19/52. Intrusion molar ortodoncia).

Informed Consent Statement: Not applicable.

Data Availability Statement: Datasets used and/or analyzed during the current study are available from the corresponding author on reasonable request.

Conflicts of Interest: The authors declare no conflict of interest.

\section{References}

1. Alexander, S.R.; Moore, R.N.; DuBois, L.M. Mandibular condyle position: Comparison of articulator mountings and magnetic resonance imaging. Am. J. Orthod Dentofac. Orthop. 1993, 104, 230-239. [CrossRef]

2. Dawson, P.E. Centric relation. Its effect on occluso-muscle harmony. Dent. Clin. N. Am. 1979, 23, 169-180.

3. He, S.S.; Deng, X.; Wamalwa, P.; Chen, S. Correlation between centric relation-maximum intercuspation discrepancy and temporomandibular joint dysfunction. Acta. Odontol. Scand 2010, 68, 368-376. [CrossRef] [PubMed]

4. Roth, R.H. Functional occlusion for the orthodontist. J. Clin. Orthod. 1981, 15, 174-199. [PubMed]

5. Crawford, S.D. Condylar axis position, as determined by the occlusion and measured by the CPI instrument, and signs and symptoms of temporomandibular dysfunction. Angle Orthod. 1999, 69, 103-115. [PubMed]

6. Dawson, P.E. Functional Occlusion: From TMJ to Smile Design; Mosby: St Louis, MO, USA, 2007.

7. Okeson, J.P. Evolution of occlusion and temporomandibular disorder in orthodontics: Past, present, and future. Am. J. Orthod. Dentofac. Orthop. 2015, 147, S216-S223. [CrossRef] [PubMed]

8. Iwasa, A.; Horiuchi, S.; Kinouchi, N.; Izawa, T.; Hiasa, M.; Kawai, N.; Yasue, A.; Hassan, A.H.; Tanaka, E. Skeletal anchorage for intrusion of bimaxillary molars in a patient with skeletal open bite and temporomandibular disorders. J. Orthod. Sci. 2017, 6, 152-158.

9. Magdaleno, F.; Ginestal, E. Side effects of stabilization occlusal splints: A report of three cases and literature review. CRANIO 2010, 28, 128-135. [CrossRef]

10. Oh, J.W.; Ahn, Y.W.; Jeong, S.H.; Ju, H.M.; Song, B.S.; Ok, S.M. Prediction of anterior open-bite development after stabilization splint treatment in patients with temporomandibular disorder. CRANIO 2020, 12, 1-10. [CrossRef]

11. Kassem, H.E.; Marzouk, E.S. Prediction of changes due to mandibular autorotation following miniplate-anchored intrusion of maxillary posterior teeth in open bite cases. Prog. Orthod. 2018, 19, 1-7. [CrossRef]

12. Dellinger, E.L.; Dellinger, E.L. Active vertical corrector treatment-long-term follow-up of anterior open bite treated by the intrusion of posterior teeth. Am. J. Orthod. Dentofac. Orthop. 1996, 110, 145-154. [CrossRef]

13. Closs, L.; Pangrazio Kulbersh, V. Combination of bionator and high-pull headgear therapy in a skeletal open bite case. Am. J. Orthod. Dentofac. Orthop. 1996, 109, 341-347. [CrossRef]

14. Shellhart, W.C.; Moawad, M.; Lake, P. Case report: Implants as anchorage for molar uprighting and intrusion. Angle Orthod. 1996, $66,169-172$.

15. Melsen, B.; Fiorelli, G. Upper molar intrusion. J. Clin. Orthod. 1996, 30, 91-96.

16. Melsen, B.; Agerbaek, N.; Eriksen, J.; Terp, S. New attachment through periodontal treatment and orthodontic intrusion. Am. J. Orthod. Dentofac. Orthop. 1988, 94, 104-116. [CrossRef]

17. da Silva, V.C.; Cirelli, C.C.; Ribeiro, F.S.; Leite, F.R.; Benatti Neto, C.; Marcantonio, R.A.; Cirelli, J.A. Intrusion of teeth with class III furcation: A clinical, histologic and histometric study in dogs. J. Clin. Periodontol 2008, 35, 807-816. [CrossRef]

18. Bayani, S.; Heravi, F.; Radvar, M.; Anbiaee, N.; Madani, A.S. Periodontal changes following molar intrusion with miniscrews. Dent. Res. J. 2015, 12, 379-385. [CrossRef] [PubMed]

19. Carrillo, R.; Rossouw, P.E.; Franco, P.F.; Opperman, L.A.; Buschang, P.H. Intrusion of multiradicular teeth and related root resorption with mini-screw implant anchorage: A radiographic evaluation. Am. J. Orthod. Dentofac. Orthop. 2007, 132, 647-655. [CrossRef] [PubMed]

20. Sugawara, J.; Baik, U.B.; Umemori, M.; Takahashi, I.; Nagasaka, H.; Kawamura, H.; Mitani, H. Treatment and posttreatment dentoalveolar changes following intrusion of mandibular molars with application of a skeletal anchorage system (SAS) for open bite correction. Int. J. Adult Orthodon. Orthognath. Surg. 2002, 17, 243-253. [PubMed]

21. Kuroda, S.; Sakai, Y.; Tamamura, N.; Deguchi, T.; Takano-Yamamoto, T. Treatment of severe anterior open bite with skeletal anchorage in adults: Comparison with orthognathic surgery outcomes. Am. J. Orthod. Dentofac. Orthop. 2007, 132, 599-605. [CrossRef]

22. Erverdi, N.; Usumez, S.; Solak, A.; Koldas, T. Noncompliance open-bite treatment with zygomatic anchorage. Angle Orthod. 2007, 77, 986-990. [CrossRef] [PubMed]

23. Akan, S.; Kocadereli, I.; Aktas, A.; Tasar, F. Effects of maxillary molar intrusion with zygomatic anchorage on the stomatognathic system in anterior open bite patients. Eur. J. Orthod. 2013, 35, 93-102. [CrossRef] 
24. Deguchi, T.; Kurosaka, H.; Oikawa, H.; Kuroda, S.; Takahashi, I.; Yamashiro, T.; Takano-Yamamoto, T. Comparison of orthodontic treatment outcomes in adults with skeletal open bite between conventional edgewise treatment and implant-anchored orthodontics. Am. J. Orthod. Dentofac. Orthop. 2011, 139, S60-S68. [CrossRef] [PubMed]

25. Buschang, P.H.; Carrillo, R.; Rossouw, P.E. Orthopedic correction of growing hyperdivergent, retrognathic patients with miniscrew implants. J. Oral. Maxillofac. Surg. 2011, 69, 754-762. [CrossRef]

26. Talaat, W.; Al Bayatti, S.; Al Kawas, S. CBCT analysis of bony changes associated with temporomandibular disorders. CRANIO 2016, 34, 88-94. [CrossRef] [PubMed]

27. Shahidi, S.; Salehi, P.; Abedi, P.; Dehbozorgi, M.; Hamedani, S.; Berahman, N. Comparison of the Bony Changes of TMJ in Patients With and Without TMD Complaints Using CBCT. J. Dent. 2018, 19, 142-149.

28. Song, F.; He, S.; Chen, S. Temporomandibular disorders with skeletal open bite treated with stabilization splint and zygomatic miniplate anchorage: A case report. Angle Orthod. 2015, 85, 335-347. [CrossRef]

29. Tanne, K.; Tanaka, E.; Sakuda, M. Association between malocclusion and temporomandibular disorders in orthodontic patients before treatment. J. Orofac. Pain 1993, 7, 156-162.

30. Tanaka, E.; Yamano, E.; Inubushi, T.; Kuroda, S. Management of acquired open bite associated with temporomandibular joint osteoarthritis using miniscrew anchorage. Korean J. Orthod. 2012, 42, 144-154. [CrossRef]

31. Fricton, J.R. Recent advances in orofacial pain and temporomandibular disorders. J. Back Musculoskelet. Rehabil. 1996, 6, 99-112. [CrossRef]

32. de Wijer, A.; Steenks, M.H.; de Leeuw, J.R.; Bosman, F.; Helders, P.J. Symptoms of the cervical spine in temporomandibular and cervical spine disorders. J. Oral. Rehabil. 1996, 23, 742-750. [CrossRef] [PubMed]

33. Alanen, P.; Kuttila, M.; Le Bell, Y. Fluctuation of temporomandibular disorders in accordance with two classifications: The Helkimo dysfunction index and treatment need grouping. Acta. Odontol. Scand. 1997, 55, 14-17. [CrossRef] [PubMed]

34. Ekberg, E.; Nilner, M. Treatment outcome of appliance therapy in temporomandibular disorder patients with myofascial pain after 6 and 12 months. Acta. Odontol. Scand. 2004, 62, 343-349. [CrossRef]

35. Mohlin, B.; Ingervall, B.; Thilander, B. Relation between malocclusion and mandibular dysfunction in Swedish men. Eur. J. Orthod. 1980, 2, 229-238. [CrossRef]

36. Williamson, E.H. Occlusion: Understanding or misunderstanding. Angle. Orthod. 1976, 46, 86-93.

37. Cordray, F.E. Centric relation treatment and articulator mountings in orthodontics. Angle. Orthod. 1996, 66, 153-158. [PubMed]

38. Pullinger, A.G.; Seligman, D.A.; Solberg, W.K. Temporomandibular disorders. Part II: Occlusal factors associated with temporomandibular joint tenderness and dysfunction. J. Prosthet. Dent. 1988, 59, 363-367. [CrossRef]

39. Seligman, D.A.; Pullinger, A.G.; Solberg, W.K. Temporomandibular disorders. Part III: Occlusal and articular factors associated with muscle tenderness. J. Prosthet. Dent. 1988, 59, 483-489. [CrossRef]

40. McNamara, J.J.A.; Seligman, D.A.; Okeson, J.P. Occlusion, Orthodontic treatment, and temporomandibular disorders: A review. J. Orofac. Pain 1995, 9, 73-90.

41. Roth, R.H. Temporomandibular pain-dysfunction and occlusal relationships. Angle Orthod. 1973, 43, $136-153$.

42. Parker, W.S. Centric relation and centric occlusion-an orthodontic responsibility. Am. J. Orthod. 1978, 74, 481-500. [CrossRef]

43. Slavicek, R. Clinical and instrumental functional analysis and treatment planning. Part 4. Instrumental analysis of mandibular casts using the mandibular position indicator. J. Clin. Orthod. 1988, 22, 566-575.

44. Magnusson, T.; Adiels, A.M.; Nilsson, H.L.; Helkimo, M. Treatment effect on signs and symptoms of temporomandibular disorders-comparison between stabilisation splint and a new type of splint (NTI). A pilot study. Swed. Dent. J. 2004, 28, 11-20.

45. Okeson, J. Management of Temporomandibular Disorders and Occlusion; Elsevier: Amsterdam, The Netherlands, 2020.

46. Moccia, S.; Nucci, L.; Spagnuolo, C.; d’Apuzzo, F.; Piancino, M.G.; Minervini, G. Polyphenols as Potential Agents in the Management of Temporomandibular Disorders. Appl. Sci. 2020, 10, 305. [CrossRef]

47. Al-Moraissi, E.A.; Farea, R.; Qasem, K.A.; Al-Wadeai, M.S.; Al-Sabahi, M.E.; Al-Iryani, G.M. Effectiveness of occlusal splint therapy in the management of temporomandibular disorders: Network meta-analysis of randomized controlled trials. Int. J. Oral. Maxillofac. Surg. 2020, 49, 1042-1056. [CrossRef]

48. McLaughlin, R.P. Malocclusion and the temporomandibular joint-an historical perspective. Angle Orthod. 1988, 58, 185-191. [PubMed]

49. Alsafadi, A.S.; Alabdullah, M.M.; Saltaji, H.; Abdo, A.; Youssef, M. Effect of molar intrusion with temporary anchorage devices in patients with anterior open bite: A systematic review. Prog. Orthod. 2016, 17, 1-13. [CrossRef] [PubMed]

50. Ramirez-Echave, J.I.; Buschang, P.H.; Carrillo, R.; Rossouw, P.E.; Nagy, W.W.; Opperman, L.A. Histologic evaluation of root response to intrusion in mandibular teeth in beagle dogs. Am. J. Orthod. Dentofac. Orthop. 2011, 139, 60-69. [CrossRef] [PubMed]

51. Daimaruya, T.; Takahashi, I.; Nagasaka, H.; Umemori, M.; Sugawara, J.; Mitani, H. Effects of maxillary molar intrusion on the nasal floor and tooth root using the skeletal anchorage system in dogs. Angle Orthod. 2003, 73, 158-166.

52. Vela-Hernandez, A.; Lopez-Garcia, R.; Garcia-Sanz, V.; Paredes-Gallardo, V.; Lasagabaster-Latorre, F. Nonsurgical treatment of skeletal anterior open bite in adult patients: Posterior build-ups. Angle Orthod. 2017, 87, 33-40. [CrossRef]

53. Hart, T.R.; Cousley, R.R.; Fishman, L.S.; Tallents, R.H. Dentoskeletal changes following mini-implant molar intrusion in anterior open bite patients. Angle Orthod. 2015, 85, 941-948. [CrossRef]

54. Crow, H.C.; Parks, E.; Campbell, J.H.; Stucki, D.S.; Daggy, J. The utility of panoramic radiography in temporomandibular joint assessment. Dentomaxillofac. Radiol. 2005, 34, 91-95. [CrossRef] [PubMed] 
55. d'Apuzzo, F.; Minervini, G.; Grassia, V.; Rotolo, R.P.; Perillo, L.; Nucci, L. Mandibular Coronoid Process Hypertrophy: Diagnosis and 20-Year Follow-Up with CBCT, MRI and EMG Evaluations. Appl. Sci. 2021, 11, 504. [CrossRef]

56. Barghan, S.; Tetradis, S.; Mallya, S. Application of cone beam computed tomography for assessment of the temporomandibular joints. Aust. Dent. J. 2012, 57 (Suppl. S1), 109-118. [CrossRef] [PubMed]

57. Molinari, F.; Manicone, P.F.; Raffaelli, L.; Raffaelli, R.; Pirronti, T.; Bonomo, L. Temporomandibular joint soft-tissue pathology, I: Disc abnormalities. Semin. Ultrasound CT MRI 2007, 28, 192-204. [CrossRef] [PubMed]

58. Hilgenberg-Sydney, P.B.; Bonotto, D.V.; Stechman-Neto, J.; Zwir, L.F.; Pachêco-Pereira, C.; Canto, G.L.; Porporatti, A.L. Diagnostic validity of CT to assess degenerative temporomandibular joint disease: A systematic review. Dentomaxillofac. Radiol. 2018, 47, 20170389. [CrossRef] [PubMed] 